\title{
Guest editors' introduction: Value modeling and business ontologies
}

\author{
Paul Johannesson ${ }^{\mathrm{a}}$ and Hans Weigand ${ }^{\mathrm{b}, *}$ \\ ${ }^{a}$ KTH Stockholm, Stockholm, Sweden \\ E-mail:pajo@dsv.su.se \\ ${ }^{\mathrm{b}}$ Tilburg University, Tilburg, The Netherlands \\ E-mail:weigand@uvt.nl
}

Ontology research can contribute to novel tools, methods and techniques for designing and developing innovative enterprise systems by providing foundational concepts for value creation, enterprise systems development and systems interoperability. A main driver for research in this area is the need to model the essence of enterprises on a level that abstracts from operational details. For this purpose, business ontologies provide abstract descriptions of enterprises in their business context, focusing on what is needed to create and transfer value. Value modeling is a business modeling approach that focuses on the value objects exchanged in business networks. Nowadays, business ontology and value modelling research is conducted using various instruments, including the Business Model Ontology (Osterwalder, 2004), the REA (Resources, Events, Agents) ontology (Geerts \& McCarthy, 2002), the Uschold et al.'s Enterprise Ontology (Dietz, 2006), the DEMO Enterprise Ontology and the e3-value tool set (Gordijn \& Akkermans, 2001).

Business ontologies are used in different ways. Typically not for the representation and search of web data, like in the Semantic Web, although this is not excluded. REA was designed originally as a basis for accounting information systems, REA models can be mapped easily to data models. Several researchers have used e3-value to substantiate the CIM level in a MDA software engineering approach and have defined synchronization rules with process models. The DEMO Enterprise Ontology can be used for the redesign of organizations and is the basis of a complete information system design method. So a major application of business ontologies is system design. However, they can also be used without a direct design goal for analysis purposes. For instance, value modeling is a tool for innovation teams to discuss and evaluate new business models.

Research on value modeling and business ontology is inherently cross-disciplinary involving the fields of computer science, information systems, business administration, philosophy, linguistics, psychology and economics. As such, it is related to the area of the Pragmatic Web, which is not only about the form or meaning of information on the Web, but also about the essence of social interaction on the Internet and its consequences for human understanding and social relationships.

\footnotetext{
${ }^{*}$ Corresponding author: Hans Weigand, TiSEM, Tilburg University, P.O. Box 90153, 5000 LE Tilburg, The Netherlands. E-mail: weigand@uvt.nl.
} 
In this issue of Applied Ontology, two papers included have their origins in the 8th International Workshop on Value Modeling and Business Ontologies (VMBO). The VMBO workshop series has been a forum for researchers in value modeling and business ontology since 2007 and has been held in Tilburg, Stockholm, Amsterdam, Ghent, Vienna, Delft and Berlin. The workshops have offered a broad coverage of the value modeling and business ontology area and have addressed topics like value modelling for service oriented design, business ontology for auditing and ontological foundations of service science. The two papers are: Frantisek Hunka, Jaroslav Zacek, "A new view of REA state machine" (Hunka \& Zacek, 2015) - in which a connection is made between REA and DEMO - and Sybren de Kinderen, Qin Ma, "Requirements engineering for the design of conceptual modeling languages" - "A goal- and value-oriented approach" (de Kinderen \& Ma, 2015) - that draws on the e3-value ontology, among others.

\section{References}

de Kinderen, S. \& Ma, Q. (2015). Requirements engineering for the design of conceptual modeling languages - A goal- and value-oriented approach. Applied Ontology, 10(1) 7-24 (this issue).

Dietz, J.L.G. (2006). Enterprise Ontology - Theory and Methodology. Berlin: Springer.

Geerts, G.L. \& McCarthy, W.E. (2002). An ontological analysis of the economic primitives of the extended-REA enterprise information architecture. International Journal of Accounting Information Systems, 3(1), 1-16.

Gordijn, J. \& Akkermans, J.M. (2001). Designing and evaluating e-business models. IEEE Intelligent Systems - Intelligent e-Business, 16(4), 11-17.

Hunka, F. \& Zacek, J. (2015). A new view of REA state machine. Applied Ontology, 10(1) 25-39 (this issue).

Osterwalder, A. (2004). The business model ontology: A proposition in a design science approach. PhD dissertation, University of Lausanne, Switzerland.

Uschold, M., King, M., Moralee, S. \& Zorgios, Y. (1998). The enterprise ontology. The Knowledge Engineering Review, 13(1), 31-89. 